\title{
Cases and Culture
}

\section{The Benefits and Risks of Narrating "Life as Lived"}

\author{
Michael A. Ashby • Leigh E. Rich
}

Received: 23 September 2012 / Accepted: 4 October 2012 /Published online: 13 November 2012

(C) Springer Science+Business Media Dordrecht 2012

Keywords Case studies $\cdot$ Risk $\cdot$ Harm $\cdot$ Narrative $\cdot$ Meaning $\cdot$ Teaching bioethics

In Utilitarianism, John Stuart Mill wrote that "[ $[\mathrm{t}]$ here exists no moral system under which there do not arise unequivocal cases of conflicting obligation" (1957, 92.25). This is what makes the practice - as well as the teaching — of bioethics so difficult and the reason that many students and members of the general populace are wont to believe that doing "the right thing" is relativistic. Engaging in careful, protracted moral reflection, particularly in cases that clearly present such "conflicting obligation," is hard. It is intellectually and emotionally taxing as well as time-consuming, requiring material resources and ongoing, honest dialogue with others. Unfortunately, our modern systems of

M. A. Ashby

Palliative Care Service, Royal Hobart Hospital, Southern Tasmania Area Health Service, and School of Medicine, Faculty of Health Sciences, University of Tasmania, 1st Floor, Peacock Building, Repatriation Centre, 90 Davey Street,

Hobart, TAS 7000, Australia

e-mail: michael.ashby@dhhs.tas.gov.au

\section{E. Rich $(\bowtie)$}

Department of Health Sciences (Public Health),

Armstrong Atlantic State University,

11935 Abercorn Street, Solms 201,

Savannah, GA 31419, USA

e-mail: leigh.rich@armstrong.edu biomedicine that train health care professionals are hard-pressed to include in curricula (in meaningful and lasting ways) "people skills," communication skills, and cultural competence, not to mention the philosophical foundations of ethics that might guide practitioners through tough cases. There are, of course, many reasons for this: The biomedical framework has been late (or errant) in formally recognizing and prioritizing these less "clinical" gaps in education; the biomedical industry in many nations leaves little time (and often fails to sufficiently reimburse) for nonmechanistic care; and society in general has increasingly become enamored with being fast, being first, being famous. One need only turn on the television, whether so-called "reality" programs or cable news, to witness contestants, broadcasters, business moguls, or politicians clamoring to cook the best food, sew the best dress, report the latest scandal, and generally beat out the competition before the clock runs out. Not only is there no reason to work together and no time for deliberation in such an environment, today's world often rewards those who "do what they have to do" to get ahead, the spoils of this mock war going to the most titillating and dramatic, not the most contemplative or most sincere. (For an interesting exploration of the rise of self-aggrandizement and "spectacle" in media, politics, education, science, and culture, see Hedges 2009.)

While it is true that time is of the essence in many health-related settings, requiring practitioners to take immediate, life-saving actions with little room for 
discussion, this only underscores the importance of training health care providers in philosophy, the social sciences, and the humanities and ensuring they have opportunities to practice non-clinical skills in addition to clinical ones. "Rapid cognition" in both clinical and non-clinical skills - as well as holistic understandings of bodies, bodies politic, health, and disease - can be honed in beneficial ways or left untutored with tragic consequences. (For example, see Gladwell's 2005 discussion of the 1999 shooting of Amadou Diallo as well as Kleinman's 1988 account of the "illness narratives" of Mrs. Flowers and her physician, Dr. Richards.)

Whether in health care or our day-to-day lives, one gets the sense that there are few opportunities for real moral engagement. Even where freedom of speech is venerated, in-depth conversation about tough issues often is avoided for fear of losing one's audience, one's "sound-bite" consistency, or one's "one-up" position. We are all out of practice, which makes those "cases of conflicting obligation" (and the teaching of bioethics) that much harder.

And that much more important.

"These are the real difficulties," Mill wrote,

the knotty points both in the theory of ethics, and in the conscientious guidance of personal conduct. They are overcome practically, with greater or with less success, according to the intellect and virtue of the individual; but it can hardly be pretended that any one will be the less qualified for dealing with them (Mill 1957, $\mid 2.25$ ).

In many disciplines, especially in medicine and bioethics, the "case study" is a familiar tool and often provides exemplars of Mill's "conflicting obligation," allowing us to practice in "real time" or retrospectively both intellectual and moral virtues. We use cases to educate and enlighten - our students, our contemporaries, and ourselves - and as an impetus to rectify and reform procedures, policies, and legislation.

This issue of the Journal of Bioethical Inquiry (JBI) is dedicated to the "case." Although every issue of the $J B I$ includes a case for which we invite and publish responses from readers, the pages that follow here offer several cases from various regions of the world as well as some commentaries (and we encourage

\footnotetext{
${ }^{1}$ Even this division line in our medico-cultural language is spurious and often counterproductive,, as the placing of patients in parentheses in order to "see" diseases as entities in themselves prioritizes only one system of knowing (see Foucault 1994).
}

others to submit more). What we hope you will find in this issue is an exploration of what it means and how useful it is-whether as practitioner, policymaker, teacher, student, or citizen - to begin a dialogue by saying, "Well, in that case ..."

Cases in general, and the cases published here, illustrate not only the messiness of "life-as-lived" but also the challenges of "life-as-emplotted," or the meaningseeking narratives we create of "life-as-lived"- that temporal succession of random, "chancy" events (Mattingly 1998). Brian Hurwitz's paper explores the implications of how a case is crafted, including who gets to tell the narrative and what "counts" in the account, as well as how a case is conveyed. While cases are "usable stories" and "deposit textual scenarios in representations that can be explored and interrogated 'on paper'mused over, elaborated on, published, debated, and analysed"-Hurwitz also emphasizes that they "distract attention away from the lived experiences and perplexities of people in the grip of circumstances, by interposing critical distance between the events and happenings themselves and the events narrated" (Hurwitz 2012, ๆ4). Because narratives manipulate "life-as-lived" in a variety of ways (for example, temporally, causally, culturally) and narrators, whether consciously, often have endings in mind even at the beginning, there is great responsibility in the construction and interpretation of narratives. Not only do bioethicists and health care providers interpret and analyze our "illness narratives," they often recast them, appropriating our primary stories into professionalized, secondary versions, further stripping them of certain details and reshaping others (Kleinman 1988; Fissell 1991).

The "moral of the story" is co-constituted in the telling of it-making awareness of the textual and contextual practices in the crafting of bioethics cases (Hurwitz 2012) an essential component in any health care encounter. The difficulty, however, is that narrative cannot tell a patient or a clinician what is right and what is wrong and is, perhaps, less of a test than, say, outcome. But in the telling of the story, its complexity and richness is revealed, and this process or unraveling may well show a clear direction for action.

The paper by Adam Feltz and Stephanie Samayoa (2012) demonstrates this well. Feltz and Samayoa, in an effort to better understand how surrogates make decisions regarding life-sustaining treatments, conducted several experiments in which participants were presented similar end-of-life cases modified in slightly 
various ways, including: whether a patient has dementia; whether a patient is young or old; whether a majority of doctors recommend continued treatment or abatement; whether a majority of peers would choose continued treatment or abatement; and whether hospital procedures are framed as "opt-in" or "opt-out." Feltz and Samayoa demonstrate that health care providers, in understanding how surrogate decision-makers rely on heuristics, "could actually improve surrogate decisions in terms of the substituted judgment standard based on advance directives" (2012, $\lceil 4$ under "General Discussion"). This is a delicate and potentially dangerous game, however, re-introducing a form of paternalism into health care. Of course, also essential for study would be the heuristics clinicians use as well.

It is not just the meta-analysis of cases as narratives that bioethicists and health care practitioners must understand and appreciate but also what specific cases can teach us. Highlighted in this issue are several case studies from different areas of the globe. The paper by Abdallah A. Adlan and Henk A.M.J. ten Have examines the risks that exist for the individuals involved as well as the larger community when a surprising finding emerges in genetic research. The case described and analyzed by Adlan and ten Have took place in Saudi Arabia and tells the events of a young family who participated in a research project conducted by their daughter's physician. According to the authors, the parents of this "13-year-old girl with severe mental and physical challenges" understood that the aim of the research "was to identify the implicated gene and compare the possible mutation of this gene to what already has been discovered by other international research centres" and offered no direct benefits to them or their daughter (2012, \1 under "The Case"). The genetic information that would become of central concern for the researchers and the "Human Ethics Committee of the hospital in which the research was being carried out," however, was that of "non-compatible paternity, meaning that - while the wife of the couple is the biological mother of the daughter-the husband is not the child's biological father" (Adlan and ten Have 2012, $\mid 2$ and $\uparrow 1$ under “The Case”).

The "Dilemma of Revealing Sensitive Information on Paternity Status in Arabian Social and Cultural Contexts" (Adlan and ten Have 2012) is nothing if not a case of "conflicting obligation," presenting questions of truth-telling; autonomy and fatherhood; trust and confidentiality in the medical encounter; informed consent; conflicts of interest; the benefits of research; and well-being and nonmaleficence, particularly in an unequally gendered environment that creates real, lifethreatening consequences for social transgression. But the case also underscores the risk of applying Western bioethical principles - as well as Western notions of legal and cultural history related to research practice and civil rights - from an "etic" (or extrinsic) perspective without fully comprehending an "emic" (or intrinsic) view. An individualistic framework-and especially one that prioritizes autonomy, veracity, and the "right to know"- misses and misunderstands the tensions in this case, which not only depicts the "conflicting obligation" in bioethical considerations in a Saudi Arabian context but also illuminates shortcomings in Western bioethics as well. (See, in particular, Paul Komesaroff's 2012 response for further discussion.)

The case Adlan and ten Have present is rich as a teaching tool in this respect and in many others, including serving as a vehicle to revisit bioethical discussions and cultural and legal histories related to genetics, disability, patient rights, and research ethics (such as informed consent, fiduciary duty, avoiding conflicts of interest and duality of roles, substituted judgment, and human subject protection). It also offers opportunities for dialogue about culture, religion, and, in particular, gender, and we especially encourage readers to submit responses that explore-both etically and emically-feminist ethics. ${ }^{2}$ Lastly, the case demonstrates that there is the possibility (however unlikely) for an ethics committee to reach a bioethically based decision, in such a case of conflicting obligation, that could result in several deaths. This gives the term "cultural safety" a particularly pressing meaning.

A second paper focusing on the ethics of genetic research by Kowal et al. (2012) looks at cultural safety dimensions of genetic testing in Indigenous communities. In a very different way-and in a very different

\footnotetext{
${ }^{2}$ It is interesting - though alarming and worrisome - that some respondents to this paper, both scholars and university students who have used this case in classroom discussions, have consciously or unconsciously readily condemned the wife as "unfaithful," "disloyal," or "dishonest" with little regard for examining and questioning the contexts in which the alleged non-paternity occurred. Again, this reveals as much, if not more, about our own cultural beliefs regarding women as well as marital and maternal social roles. Like Hurwitz and other scholars who study the construction of narrative suggest, we must not overlook our own cultural, religious, racial, gender, etc., biases that are veiled - or unveiled - in the discussions of cases.
} 
cultural setting — Kowal et al.'s "Genetic Research and Aboriginal and Torres Strait Islander Australians" explores many of the same ethical issues as the paper by Adlan and ten Have. Both cases highlight the long overdue need for further work in bioethics within nonWestern and non-individualistic contexts. Specifically, Kowal et al. discuss the potential harms of genetic research in Indigenous populations, "including a lack of benefit to their communities, a diversion of attention and resources from non-genetic causes of health disparities and racism in health care, a reinforcement of 'victim-blaming' approaches to health inequalities, and possible misuse of blood and tissue samples" (Kowal et al. 2012, under "Abstract"). This list, of course, easily could be applied to non-Indigenous settings as well, inviting improvement in ethical understandings and scientific conduct with regard to genetic research and testing everywhere. ${ }^{3}$

The paper, which presents the case of the (pseudonymous) Remote Aboriginal Project (RAP), also offers a positive example of how researchers and communities can develop genetic studies together. The RAP

research team was composed of non-Indigenous genetic researchers who had extensive experience working in developing countries ... a Research Institute (RI) with a long history of working with Aboriginal communities ... Aboriginal researchers within and outside the RI ... [and] the boards of the local community-owned Aboriginal health service (AHS) and of a regional, community-owned Aboriginal education community (AEC) ... [which] comprised, respectively, elders and leaders of local families serviced by the AHS and parents of children at the AEC (Kowal et al. 2012, $\uparrow 1-\uparrow 2$ under "The Case").

Kowal et al. note, however, that such cooperative projects require both time (e.g., RAP was proposed only after "an extended phase of consultation over four years" and several presentations to and negotiations with the community and an Aboriginal Research Ethics

\footnotetext{
$\overline{3}$ For example, how often do patients considering genetic testing in Western cultures understand that successful results usually necessitate that other family members be tested-family members who might not wish to undergo testing and/or have the means to afford the test itself and the potential physical, psychological, and financial consequences? Moreover, even when only an individual is tested, genetic information learned from such testing may affect blood relatives who did not seek out this knowledge.
}

Committee) and additional resources (for, e.g., "the use and storage of samples and obtaining individual consent for future research ... not contained in the [original] Memoranda of Understanding”) (Kowal et al. 2012, \1 under "The Case" and $\$ 4$ under "Discussion and Conclusions").

"Time" and "additional resources" could be said to be another common theme in this issue. Two papers by Rice et al. (2012) and Tuck Wai Chan and Desley Hegney (2012) present cases related to the end of life and the necessity of health care professionals to possess sufficient time and communication and cultural skills to assist patients in enacting their wishes.

"When patients, for reasons of general medical or psychiatric illness, fail to verbally communicate," Rice et al. emphasize, "providers must be receptive to messages conveyed through alternate avenues of communication" (2012, under "Abstract"). To illustrate this, they describe the plight of "a socially isolated 58-year-old veteran with schizophrenia and dialysis-dependent renal disease" who refused both medical care and food during hospitalization. The patient also seemed to attempt suicide by "fray[ing] an in-room appliance's live electrical cord" (Rice et al. 2012, $\uparrow 1$ and $\uparrow 4$ under "The Case") placing health care providers in a quandary between respecting the patient's autonomy over his care and protecting the patient against self-harm.

At the heart of the matter, however, was not the patient's apparent "incapacity" but, rather, the incapacity of health care systems and legal systems to engage with individuals at multiple levels. "Early in his treatment," Rice et al. note, "[the patient] acknowledged that he wasn't suicidal, but that he had acted to 'let people know that no one was listening to me.' ... He had no suicidal intent but nonetheless felt prepared to risk his life in order to uphold his autonomy" (2012, 94 under “The Case” and \3 under "Discussion").

Like the Adlan and ten Have case discussed above, a seemingly bioethically based decision - that of respecting one's autonomy to refuse care-risked the life of a patient who merely wished not to be overlooked during medical decision-making, regardless of the "non-standard" means used for communication. Rice et al. warn: "Current legal standards of care for the incapacitated patient, in which providers look to health care proxies for treatment decisions ... may further distract providers from patient communication by encouraging engagement with the proxy in lieu of the patient" (2012, 『2 under “Introduction"). 
Chan and Hegney (2012), in a related vein, examine the end of life in the Buddhist tradition and show how harms can be done to dying adherents by a failure to understand the Buddhist constructs of body and mind. What counts as "medically futile" may be understood differently in a Buddhist context. Presenting the case of a "72-year-old Buddhist man [who] suffered a cardiac arrest and was placed on life support and intravenous medication," Chan and Hegney explain that "if medical treatment can decrease suffering without altering the clarity of the mind, then a treatment should not be considered futile" (2012, under “Abstract”). Moreover:

Health professionals should also realise that, to the Buddhist, the mind is not in the brain. The mind, like the body, is constantly changing. A diagnosis of brain death, for example, would not convince practising Buddhist families that their relative has ceased to live, particularly if the heart is still beating and the person is still breathing. ...

Although there is a moral precept against intentional killing, withdrawal of treatment and letting a person die of natural causes would be acceptable in Buddhist doctrine, if the intention is to reduce further suffering and the actions taken do not interfere with the ability of the mind to complete its tasks at the time of death. In contrast, participating in unnatural shortening of the lifespan is not good Buddhist practice and has karmic implications. In this case study, the Buddhist family were agreeable to removing the medications that might unnaturally keep the heart beating, but were not convinced by the brain death diagnosis that the mind of their father was ready to move from this life (and, thus, were not ready to remove the other forms of life support) (Chan and Hegney 2012, \1-\$2 under “Conclusion”).

The case of this Buddhist patient, as well as the other cases presented here, underscores the importance of those "people skills," communication skills, and cultural competence within any health-related encounter and the necessity of significant time and attention to in-depth and revisited dialogue among all parties involved.

Anything less risks causing harm, not only to the individual and his or her family but also to the practice of medicine, the discipline of bioethics, and society-atlarge.

The avoidance of harm is a paramount concern to everybody in all areas of life. Whether it is accident prevention in the home or at work or school or harm reduction in public health, genetic research, or decisionmaking at the end of life, the stakes may vary but the challenge does not. (This is a problematical balance because risk-reduction also has the capacity to infringe liberty, intrude into the conduct of everyday life, suppress spontaneity, and stifle creativity. In short, the collective societal desire to be safe may also make life dull, and adherence to procedure and regulation, however wellintentioned, can detract from the true purpose of "safety." Mill also said that the only reason for governments to limit our individual freedom is for the prevention of harm to others, so, perhaps for him, ethics, at least as a study of difference, starts where harm may be caused.)

Harm reduction or avoidance is clearly an obligation that is imposed upon all those concerned with the life and health sciences and is, therefore, a central concern of bioethics, as seen in this issue.

To that end, the presentation of cases as teaching tools and windows into other cultures as well as our own is useful, not only as a method for attempting to confront and disentangle "conflicting obligation" but also as the very stuff of an "examined life."

Another type of risk exists, however, anytime we take a primary account of a health care episode and create secondary accounts - predominantly the risk of tossing aside crucial information simply because "it doesn't belong" in the frameworks in which we are entrenched.

We hope this issue of the $J B I$ - which also includes papers “Addressing Ethical Considerations and Authors' Conflict of Interest Disclosure in Medical Journals in Iran" (Heidari et al. 2012), "Professional Ethics in Context: Practising Rural Canadian Psychologists" (Malone 2012), and "Factors Encouraging and Inhibiting Organ Donation in Israel" (Sperling and Gurman 2012) as well as book reviews of John Glad's Jewish Eugenics (Dorff and Berger 2012) and Hugh B. Urban's The Church of Scientology (Rich 2012)_offers insight into both "Cases and Culture" that will be valuable for the practice of health care and policymaking.

\section{References}

Adlan, A.A., and H.A.M.J. ten Have. 2012. The dilemma of revealing sensitive information on paternity status in Arabian social and cultural contexts: Telling the truth about paternity in Saudi Arabia. Journal of Bioethical Inquiry 9(4): doi:10.1007/s11673-012-9390-y. 
Chan, T.W., and D. Hegney. 2012. Buddhism and medical futility. Journal of Bioethical Inquiry 9(4): doi:10.1007/ s11673-012-9392-9.

Dorff, E.N., and I. Berger. 2012. Review of Jewish eugenics, by John Glad. Journal of Bioethical Inquiry 9(4): doi:10.1007/ s11673-012-9395-6.

Feltz, A., and S. Samayoa. 2012. Heuristics and life-sustaining treatments. Journal of Bioethical Inquiry 9(4): doi:10.1007/ s11673-012-9396-5.

Fissell, M.E. 1991. The disappearance of the patient's narrative and the invention of hospital medicine. In British medicine in the age of reform, ed. R. French and A. Wear, 92-109. New York: Routledge.

Foucault, M. 1994. The birth of the clinic: An archaeology of medical perception. Trans. A.M. Sheridan Smith. New York: Vintage Books. Originally published as Naissance de la clinique (Paris: Presses Universitaires de France, 1963).

Gladwell, M. 2005. Blink! The power of thinking without thinking. New York: Little, Brown and Company.

Hedges, C. 2009. Empire of illusion: The end of literacy and the triumph of spectacle. New York: Nation Books.

Heidari, A., S.H. Adeli, S. Mehravaran, and F. Asghari. 2012. Addressing ethical considerations and authors' conflict of interest disclosure in medical journals in Iran. Journal of Bioethical Inquiry 9(4): doi:10.1007/s11673-012-9393-8.

Hurwitz, B. 2012. Textual practices in the craft of bioethics cases. Journal of Bioethical Inquiry 9(4): doi:10.1007/ s11673-012-9407-6.

Kleinman, A. 1988. The illness narratives: Suffering, healing, and the human condition. New York: Basic Books.
Komesaroff, P.A. 2012. Cross-cultural issues in ethics: Context is everything. Commentary on "The dilemma of revealing sensitive information on paternity status in Arabian social and cultural contexts" by Abdallah A. Adlan and Henk A.M.J. ten Have. Journal of Bioethical Inquiry 9(4). doi:10.1007/s11673-012-9402-y.

Kowal, E., G. Pearson, C.S. Peacock, S.E. Jamieson, and J.M. Blackwell. 2012. Genetic research and Aboriginal and Torres Strait Islander Australians. Journal of Bioethical Inquiry 9(4): doi:10.1007/s11673-012-9391-x.

Malone, J.L. 2012. Professional ethics in context: Practising Rural Canadian psychologists. Journal of Bioethical Inquiry 9(4): doi:10.1007/s11673-012-9394-7.

Mattingly, C. 1998. Healing dramas and clinical plots: The narrative structure of experience. Cambridge: Cambridge University Press.

Mill, J.S. 1957. In Utilitarianism, ed. O. Piest. New York: Liberal Arts Press.

Rice, T.R., Y. Dobry, V. Novakovic, and J.M. Appel. 2012. The importance of patient-provider communication in end-oflife care. Journal of Bioethical Inquiry 9(4). doi:10.1007/ s11673-012-9397-4.

Rich, L.E. 2012. Review of The Church of Scientology: A history of a new religion, by Hugh B. Urban. Journal of Bioethical Inquiry 9(4). doi:10.1007/s11673-0129409-4.

Sperling, D., and G.M. Gurman. 2012. Factors encouraging and inhibiting organ donation in Israel: The public view and the contribution of legislation and public policy. Journal of Bioethical Inquiry 9(4): doi:10.1007/s11673-012-9398-3. 